\title{
PRE-RACE DROP-OUT IN MARATHON RUNNERS: REASONS FOR WITHDRAWAL AND FUTURE PLANS
}

\author{
P. J. CLOUGH, MA, S. DUTCH, MSc*, R. J. MAUGHAN, PhD and J. SHEPHERD, BSc** \\ Department of Environmental and Occupational Medicine and Department of Psychology**, University of Aberdeen
}

\begin{abstract}
This study examines the reasons given for non-participation in the 1984 Aberdeen Milk Marathon by those people who entered for the race but did not run. The major reason was found to be injury during training. The future running plans of the sample were also investigated and it was found that the vast majority aimed to continue marathon running. Around twothirds of the sample had decided not to run at least two weeks before the day of the race. A third of the respondents indicated that they would have taken part in the race had there been a half marathon option.
\end{abstract}

Key words: Pre-race drop-out, Marathon running, Injuries, Future intentions

\section{INTRODUCTION}

The effects on participants of running have recently begun to receive some research attention. Apart from the physiological benefits associated with increased fitness (e.g. Katch, 1976), a number of psychological factors have been found to show improvement including self-concept (e.g. Sharp and Reilly, 1975) and general mood states (e.g. Ledwidge, 1980). Information on pre-race drop-outs is however very sparse. Fletcher and Eadie (1986) examined pre-race drop-outs from the 1983 Glasgow Marathon and reported that the major causes were injury and illness during training. They also reported on some motivational differences between runners and non-runners.

The aim of the present study was to identify the reasons behind pre- and during-race drop-out in the 1984 Aberdeen Marathon. Whilst this is not as big a problem as that faced by the two major mass marathons of Glasgow and London, which have to reject a number of applicants each year, a large number of drop-outs can produce many administrative problems. A more serious problem lies in the possibility that people who are forced to drop out of a marathon may become disillusioned with marathon running in particular and perhaps even running in general. In order to examine this question the future running plans of this drop-out sample were also investigated.

\section{MATERIALS AND METHODS}

The Aberdeen Milk Marathon was held on Sunday, 15th September, 1984. Whilst the race attracted 2,462 entrants, only 1,313 finishers were noted. The weather on the day of the race was very windy and far from ideal for a marathon. Shortly after the race a questionnaire was sent out to all those whose names appeared on the list of entrants but not on the list of finishers. The questionnaire was designed to elicit information on 4 main areas: biographical, training regimens, reasons for non-participation and future running plans. Statistical analysis of the data was carried out úsing the SPSSX package run on a Honeywell 60/80 system. Student t-tests for independent groups and chi-squared tests were used where appropriate.

Address for correspondence:

Mr. P. J. Clough

Department of Environmental and Occupational Medicine

University Medical School

Aberdeen AB9 2ZD

*Present address:

Social Work Department, Royal Aberdeen Children's Hospital

\section{THE SAMPLE}

A total of 502 replies were received: $\mathbf{4 4 3}$ from males and 59 from females. This gave an overall response rate of $43 \%$. The average age of the respondents was $31 \pm 8$ years (mean \pm SD). The average weekly mileage in the 6 months before the race was $31 \pm 17$ miles with the longest single run averaging $14 \pm 6$ miles. The respondents had been training for a mean period of 14 months but they did show considerable variability, with training periods varying from over 5 years to none at all. Whilst the sample studied included 225 runners $(44 \%)$ who had not previously run a marathon, it is worth noting that over half of the pre-race drop-outs had completed at least one previous marathon race.

\section{RESULTS AND DISCUSSION}

Of the 502 non-finishers surveyed only $18(4 \%)$ actually started the race, with the majority of these $(n=12)$ being forced to stop at the 11-15 mile stage due mainly to injury $(n=8)$ and cramp $(n=3)$. The main aim of this study however was to examine the reasons behind runners' nonparticipation in a race they had entered. The questionnaire was designed so that the runners, if they wished, could give more than one reason for their non-participation in the race. In total, 96 of the 484 non-runners $(20 \%)$ gave more than one reason, with the dominant combination being that of injury leading to lack of training $(n=52)$. A full breakdown of the reasons for withdrawal is presented in Table $I$.

TABLE I

Reasons given for pre-race drop-out

\begin{tabular}{lrrrrrrr}
\hline & Males & \multicolumn{2}{c}{ Females } & \multicolumn{2}{c}{ Total* } \\
\hline Injury & 190 & $(42 \%)$ & 13 & $(22 \%)$ & 203 & $(42 \%)$ \\
Illness & 65 & $(15 \%)$ & 11 & $(17 \%)$ & 76 & $(16 \%)$ \\
Absent from Aberdeen & 63 & $(14 \%)$ & 9 & $(15 \%)$ & 72 & $(15 \%)$ \\
Loss of interest & 18 & $(4 \%)$ & 2 & $(3 \%)$ & 20 & $(4 \%)$ \\
Lack of training & 110 & $(25 \%)$ & 23 & $(39 \%)$ & 133 & $(27 \%)$ \\
Weather conditions & 3 & $(0)$ & 3 & $(5 \%)$ & 6 & $(1 \%)$ \\
Other & 42 & $(9 \%)$ & 11 & $(17 \%)$ & 53 & $(11 \%)$ \\
Missing data & 19 & $(4 \%)$ & 3 & $(5 \%)$ & 22 & $(5 \%)$ \\
& & & & & & &
\end{tabular}

* Note that runners could give more than one reason for not running therefore the percentages add up to more than $100 \%$.

\section{INJURY}

It can clearly be seen that injury is the most common reason that the respondents gave for not taking part in the race. As well as showing the greatest impact on the non-participants 
in its own right it was also a major factor in the lack of training reported by a number of runners, accounting for at least $40 \%$ of this category. Because of the importance of injuries in dictating running activity within this sample an analysis of the site of injury is reported in Table II.

TABLE II

Site of injuries incurred during preparation for the marathon in relation to the site of injury

\begin{tabular}{lrc}
\hline Site of injury & $\begin{array}{c}\text { Number of injured } \\
\text { runners reporting } \\
\text { site of injury }\end{array}$ & $\begin{array}{c}\text { Percentage of injured } \\
\text { runners reporting } \\
\text { site of injury }\end{array}$ \\
\hline Foot & 17 & $8 \%$ \\
Ankle & 18 & $8 \%$ \\
Achilles tendon & 7 & $3 \%$ \\
Shin & 6 & $2 \%$ \\
Calf & 5 & $2 \%$ \\
Knee & 52 & $26 \%$ \\
Hamstring & 3 & $1 \%$ \\
Groin & 2 & $1 \%$ \\
Hip & 9 & $4 \%$ \\
Back & 9 & $4 \%$ \\
Neck & 2 & $1 \%$ \\
Other & 16 & $8 \%$ \\
Non-running & & $16 \%$ \\
sporting injuries & 32 & $3 \%$ \\
Non-sporting injuries & 6 & $9 \%$ \\
Not stated & 19 & \\
\hline
\end{tabular}

A statistical analysis of the injured vs. the non-injured revealed no significant differences in their training regimens or their experience of marathon running. This seems to suggest that it was not over-training or inexperience that led to these runners getting injured.

The injuries noted are those that might be expected considering the training demands associated with marathon running and correspond to those noted by Maughan and Miller (1983) in runners who actually took part in the 1982 Aberdeen Marathon. It is also worth noting the high incidence of non-running injuries amongst the prerace drop-outs.

\section{TIME OF WITHDRAWAL}

Overall two-thirds of this sample decided not to run at least two weeks before the race was to be held. Time of withdrawal did vary depending on the reasons behind it. Forty per cent of illness sufferers decided not to take part on the day of the race itself, whereas $56 \%$ of those who were injured had decided not to run at least two weeks before the date of the race. These results indicate that if some form of confirmation system were to be employed in the final two weeks before the race then the field size could be estimated to a much greater degree of accuracy. This would provide the race organisers with a number of tangible benefits e.g. a more accurate idea of the facilities needed on the day of the race.

Another finding that will be of special interest to race organisers is that $33 \%$ of the sample surveyed stated that they would have taken part in the race had there been a half marathon option within it. Not surprisingly the main reason given by this group for non-participation was lack of training. It seems that one way to optimise the number of people who turn up on the day is to hold 'a race within a race'.

\section{FUTURE INTENTIONS}

Only 8 respondents $(2 \%)$ said that they would stop running altogether and 7 of these had received serious long-term injuries. Future plans regarding marathon running were also assessed and it was found that $85 \%$ of the drop-out sample intended to run another, or in some cases their first, marathon race. Although no measure of the respondents' actual subsequent behaviour is available, it does appear that disillusionment had not set in for the vast majority.

\section{ABSENT FROM ABERDEEN}

The relatively high percentage of people withdrawing due to being absent from Aberdeen probably reflects the nature of the employment pattern prevalent in the city. Many workers were employed offshore and were liable to be sent away at short notice.

\section{CONCLUSION}

This study was designed as a pilot project for a more ambitious investigation into drop-outs, which will include a direct comparison between runners and non-runners on a number of demographic and motivational criteria. It is hoped that by following the recommendations made by Dillman (1978), regarding questionnaire design, that a higher response rate will be achieved than has been obtained both in this study and in previous work in this area.

Despite the poor response rate, which therefore makes any conclusions necessarily speculative, a number of interesting findings do emerge from this study. The major reason for withdrawal appears to be injuries received whilst preparing for the race, although these do not seem to be related to runner experience. These findings provide some support for the conclusions drawn by Fletcher and Eadie (1986). The injuries noted were predominantly to the lower limbs, most notably the knees.

The findings regarding the timing of drop-outs and the benefits of including half marathons within full marathon races should be of use to race organisers. Finally nonparticipation in one particular marathon does not seem to deter the vast majority of runners from pursuing future involvement in the sport.

\section{ACKNOWLEDGEMENTS}

This study was supported by a grant from the Health Promotion Research Trust. Dr. R. J. Maughan is supported by a grant from Shell Expro (UK) Ltd.

\section{References}

Fletcher, K. P. and Eadie, D., 1986 "Pre race drop-out from the Glasgow Marathon". Brit.J.Sports Med. 20: 74-76.

Dillman, D., 1978. Mail and telephone surveys: the total design method. Wiley, New York.

Ledwidge, B., 1980 "Run for your mind: aerobic exercise as a means of alleviating anxiety and depression". Canad.J.Behav.Sci.Comp 12 (2): 126-140.

Katch, F., 1986 "The effects of exercise on the aging process". The Phys. and Sports Med. 4: 66-68.

Maughan, R. J. and Miller, J. D., 1983 "Incidence of training-related injuries among marathon runners". Brit.J.Sports Med. 17: 162-165.

Sharp, M. W. and Reilly, R. R., 1975 "The relationship of aerobic physical fitness to selective personality traits". J.Clin.Psy. 31: 428-430. 